\title{
Assessment of Animal Bites in Selected Veterinary Establishments in Plateau State: A Three Year Review.
}

\author{
Akosu $\mathrm{TJ}^{1}$, Afolaranmi TO${ }^{1}$, Fayenuwo $\mathrm{JO}^{2}$, Kumbak $\mathrm{FD}^{2}$, Okorie $\mathrm{CG}^{2}$, Adamu $\mathrm{U}^{2}$, Iduh $\mathrm{DE}^{2}$, \\ Ntung $\mathrm{S}^{2}$, Zoakah $\mathrm{AI}^{1}$ \\ Correspondence: Akosu TJ e-mail - akosu2002@yahoo.co.uk Phone-+2348065813415 \\ 'Department of Community Medicine, University of Jos \\ ${ }^{2}$ Department of Community Medicine, Jos University Teaching Hospital Jos.
}

\section{Abstract}

Background: Animal bites are common and sometimes result in the transmission of preventable diseases with high morbidity and fatality. This study sought to determine the pattern of animal bites reported in selected veterinary establishments in Plateau State and the vaccination status of the animals involved.

Methods: This was a 3 year retrospective study of vertebrate animal bites of humans reported to 2 public veterinary centres in Jos. Data were extracted from the records of the centres and analysed using SPSS version 21.0.

Results: There were 898 bites reported during the period, about one third (33.3\%) of which were in children 1-10 years old. Over half of the victims $(52.6 \%)$ were males and most (72.2\%) resided in urban areas. Almost all the bites (97.9\%) were from dogs, with local dogs accounting for $67.7 \%$ of dog bites. The lower limbs were the commonest site of bites and $80 \%$ of bites were unprovoked. Though $80.2 \%$ of animals responsible for the bites had identifiable owners, $56.7 \%$ had no record of rabies vaccination. Among the animals with vaccination records, $78.9 \%$ had either never been vaccinated or their vaccinations had expired. Only 21.1\% were fully vaccinated. Median time from bite to presentation at the veterinary centres was 1 day (IQR 0.5-2.0 days)

Conclusion: Bite injuries from unvaccinated dogs remain a major public health problem in Plateau State. Urgent efforts should be made to enlighten dog owners and reduce the incidence of bites.

Keywords: Animal bites, Rabies, Veterinaryestablishments.

\section{Introduction}

Human-animal relationship has existed for several centuries with several advantages and some known disadvantages. Domestic animals kept in the home as pets often act as "social substitutes" through bonding; and some evidence has shown that pet presence at home may induce wellbeing in people and the development of social skills in children. ${ }^{1}$ In the industrialized countries, some animals like dogs have been put to remarkably high adaptation to human needs in health promotion, adjustment of the elderly, recovery from illnesses, guiding the blind, assisting the deaf, assisting persons that are impaired in their mobility as well as to alert epileptic patients that their seizure is imminent. ${ }^{2}$ In this part of the world, however, animals are 
kept for various reasons including companionship as pets, house guards, assistants for hunting of wildlife and as food that is eaten by some people. These reasons and many more account for the close contact between humans and domesticated animals.

Proper identification and management of the positive and negative aspects of this relationship between humans and animals is vital, as some domesticated animals such as dogs, cats and monkeys have been associated with bite injuries in humans. Though bites from domestic animals are common, animal bites could also come from wild animals. Human activities involving the exploration of forests and caves, like hunting and gathering of wood, have brought man in contact with animals residing in the wild. These animals which include bats, foxes and skunks may also be sources of bite injuries to humans. ${ }^{1,7}$

Animal bites are important because they could serve as a route of transmission of preventable diseases such as tetanus and rabies, which once established, could be highly fatal. One proven way to prevent the complications following bite from animals is by early initiation of post-exposure prophylaxis for rabies and tetanus prevention. However, this is dependent on early presentation to relevant health centres where appropriate interventions can be commenced as soon as possible. These health centres are mostly, but not restricted to, veterinary health centres which could be private or state owned, where appropriate post exposure prophylaxis could be administered following a report of animal bite; and the offending animal could be followed up and examined for rabies infection.

Animal bites are a major public health threat both in developed and developing nations. ${ }^{3}$ This makes the need for laws guiding report following animal bite very important. Various places in the developed world have local laws guiding the reporting of animal bite. For example, Section 11.03 of the New York City Health Code requires all animal bites to be reported within 24 hours of the event. ${ }^{4}$ However, this is not the case in most developing nations where these laws are non-existent, inadequate or even if they exist, are not enforced. The implication of this is that most cases of animal bite in a developing country like Nigeria will be reported only at the discretion of the victim or when the victim is forced to seek help following complications. Also of interest is the fact that animal bites are more common among children less than 16 years, who may not report minor scratches or bites to their caregivers.

In Plateau State, as in many other communities, most animal bites come from dogs which are the main reservoir of the rabies virus. ${ }^{3}$ There is a high dog population in the State which could be due to the fact that most communities use dog meat as food. Previous studies indicated that majority of dog bites in the State, as in other places, were from unvaccinated dogs or those with unknown records of rabies vaccination. ${ }^{5,6}$ The implication of this is that majority of the victims were at risk of contracting rabies if they did not receive prompt and complete post exposure prophylaxis. It is not known if the findings of these studies were used to increase awareness among dog owners of the need to fully vaccinate their dogs and thus increase vaccination coverage and other preventive measures. The purpose of this study therefore was to determine the pattern of animal bites in Plateau state and the vaccination status of the animals responsible. 


\section{Methods}

Plateau State is located in the North Central region of Nigeria between latitude $80^{\circ} 22^{\prime}$ and $100^{\circ} 20^{\prime}$ North and longitude $80^{\circ}$ $32^{\prime}$ and $100^{\circ} 38^{\prime}$ East. It has an estimated land area of 26,890sq.km and a projected population of $4,131,870(2,060,436$ males and 2,071,434 females). ${ }^{8}$ Majority of the population live in rural areas and practice subsistent farming. Common domestic animals in the State include dogs, goat, sheep, birds and cats which are used for various purposes including food, security, hunting and as pets.

The State has 964 public and private health facilities, two public veterinary clinics and several private veterinary clinics. The study was carried out in 2 public veterinary facilities - National Veterinary Research Institute, Vom and University of Jos Veterinary Clinic. Ethical approval was obtained from the Jos University teaching Hospital Ethics committee.

Retrospective data on animal bites and scratches to humans reported to the two veterinary centres from January 2014 to December 2016 (3-year period) was retrieved using a structured data extraction tool. All patients that presented at the centres within the study period were included in the study. However, invertebrate animal bites and improperly documented vertebrate bites were excluded.

Information obtained from the records included socio-demographic characteristics of patients, date and place of bite, species of biting animal and their owner if known, diagnostic results where the heads of killed biting animals were available for laboratory examination, site on the body the bite occurred, initial post exposure treatment (PET) received prior to presentation, and any other relevant information. The investigators personally filled the data extraction tool to ensure validity. Data was cleaned and analysed using SPSS Version 21.

\section{Results}

The records of 898 reported cases were retrieved and analysed. Their ages ranged from 1-90 years but the preponderant age group was the 1-10 years group. Most; 648 $(72.2 \%)$ of the bite victims were urban dwellers and majority; 472 (52.6\%) were males. Table 1.

Nearly all the bites; 879 (97.9\%) were by dogs and the local dogs accounted for 595 $(67.7 \%)$ of all the dog bites. Male dogs were responsible for more bites compared to females. There was one case each of fox and monkey bites. Table 2. There were more bites in the morning hours compared to the afternoon and evening hours. Over $90 \%$ of the bites affected the limbs with the lower limbs dominating and about 4 of every 5 bites were from an unprovoked attack (Fig $1 \& 2$ ).

Though $720(80.2 \%)$ of the animals responsible for the bite had identifiable owners, $509(56.7 \%)$ of the animals had unknown record of rabies vaccination. Out of the 389 animals with vaccination records, $307(78.9 \%)$ had their vaccinations expired or had never been vaccinated while only $82(21.1 \%)$ had correct records of up to date vaccination.

Out of the 898 cases, $595(66.2 \%)$ presented to the health facility within 24 hours of the animal bite. The median time from bite to presentation was 1 day (IQR = 0.5- 2.0 days). Post exposure treatment given prior to presentation was appropriate in $477(53.1 \%)$ of cases while in 387 (43.1\%) of cases, nothing was done before presenting to the facility. Table 3 
Table 1: Socio-demographic characteristics of the bite victims

\begin{tabular}{lcc}
\hline Variable & Frequency & Percentage (\%) \\
\hline Age group & & \\
$0-10$ & 299 & 33.3 \\
$>10-20$ & 185 & 20.6 \\
$>20-30$ & 132 & 14.7 \\
$>30-40$ & 121 & 13.5 \\
$>40-50$ & 85 & 9.5 \\
$>50-60$ & 45 & 5.0 \\
$>60$ & 31 & 3.5 \\
Total & 898 & 100.0 \\
Sex & & \\
Male & 472 & 52.6 \\
Female & 426 & 47.4 \\
Total & 898 & 100.0 \\
Place of Residence & & \\
Rural & 250 & 27.8 \\
Urban & 648 & 72.2 \\
Total & 898 & 100.0 \\
\hline
\end{tabular}

Table 2: Characteristics of the biting animal

\begin{tabular}{lcc}
\hline Variable & Frequency & Percentage (\%) ) \\
\hline Animal & & \\
Dog & 879 & 97.9 \\
Cat & 15 & 1.7 \\
Goat & 2 & 0.2 \\
Monkey & 1 & 0.1 \\
Fox & 1 & 0.1 \\
Total & 898 & 100 \\
Breed of Dog & & \\
Local & 595 & 67.7 \\
Mongrel & 188 & 21.4 \\
Caucasian & 46 & 5.2 \\
Alsatian & 27 & 3.1 \\
Neopolitan & 4 & 0.5 \\
Rottweiler & 3 & 0.3 \\
Terrier & 2 & 0.2 \\
Unknown & 14 & 1.6 \\
Total & 879 & 100 \\
Sex of Dog & & \\
Male & 489 & 55.6 \\
Female & 376 & 42.8 \\
Unknown & 14 & 1.6 \\
Total & 879 & 100 \\
\hline
\end{tabular}




$\begin{array}{lrl}\text { Head } & (0) \\ \text { Face } & (11) \\ \text { Back } & (9) \\ \text { Chest } & (4) \\ \text { Arm } & (2) \\ \text { Abdomen } & (10) \\ \text { Hand } & (103) \\ \text { Finger } & (46) \\ \text { Buttocks } & (42) \\ \text { Penis } & (1) \\ \text { Thigh } & (31) \\ \text { Knee } & (0) \\ \text { Leg } & (203) \\ \text { Ankle } & (1) \\ \text { Feet } & (3)\end{array}$

Figure 1: Distribution of dog bite injuries by gender and anatomical sites

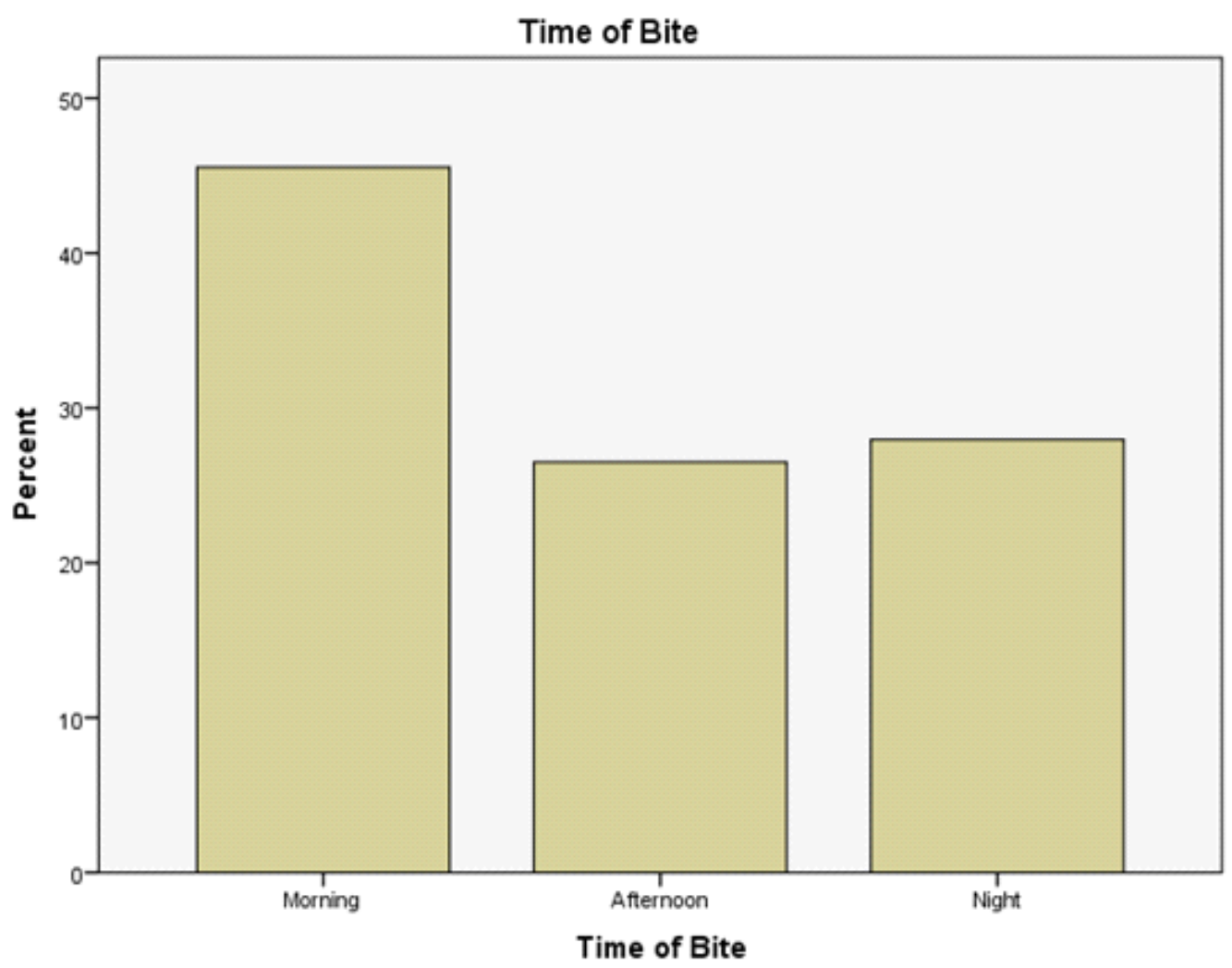

Figure 2: Distribution of times of the animal bites. 
Table 3: Status of the biting animal

\begin{tabular}{lcc}
\hline Variable & Frequency & Percentage (\%) \\
\hline Ownership of animal & 720 & \\
Owner identified & 178 & 80.2 \\
Owner not identified & 898 & 19.8 \\
Total & & 100 \\
Rabies vaccination records & 389 & 43.3 \\
Available & 509 & 56.7 \\
Unavailable & 898 & 100 \\
Total & 307 & 78.9 \\
Vaccination status of animals with records & 82 & 21.1 \\
Expired/never vaccinated & 389 & 100 \\
Vaccination up to date & & \\
Total &
\end{tabular}

\section{Discussion}

The study identified that the paediatric and young age groups were most at risk from animal bite, and the prevalence of animal bite seem to decrease as the age group increases. This is similar to the findings in the USA and Iran. ${ }^{10,11}$ The reason for this could be that children and young people are more fond of animals, have higher curiosity but are more vulnerable to animal attacks because of their age and size. They also have a higher tendency to provoke animals and yet have less experience in defending themselves from an attack. ${ }^{12}$ The study also revealed that more cases were reported from those residing in urban areas than from rural areas. This is perhaps due to ignorance of the need to report such bites on the part of the rural dwellers and/or lack of access to health facilities. This urban preponderance is similar to the results seen in other previous studies. ${ }^{12,13}$

Majority of the animal bites were from dogs, with the local and mongrel breeds accounting for majority of cases. This is also in keeping with findings from studies in other parts of the world. ${ }^{10,11,14}$ Dogs are easily the most common domesticated animals and the local and mongrel breeds are both relatively cheaper and less technical to procure and rear in our environment. In addition, meat from local dogs is a delicacy on the Plateau, thus most people keep them for food.

While the most frequently bitten body part was the limbs, children were more predisposed to bites on the head and face due to their stature. ${ }^{15}$ Majority of bites were from an unprovoked attack. This is worrisome given that most of the owners of these offending animals could not be identified. This could be due to the fact that in Nigeria, animal ownership is poorly regulated and people allow their animals to roam about freely thereby increasing the risk of a human attack. The import of bites from stray animals is that following the bite incident the vaccination status of the offending animal is not immediately known making management of the victims challenging. Our finding that most animals implicated in bite injuries had identified owners is consistent with other similar studies and provides some reassurance since such animals could be more easily observed for signs of rabies as part of the management of the victim. ${ }^{5,15}$ Majority of the bites occurred in the morning period. This could be as a result of the exposure of people to animals while travelling to school or work. 
The vaccination status of most animals implicated in reported bite incidents could not be ascertained. Only a small proportion $(9.1 \%)$ of the animals were fully vaccinated with evidence of a vaccination card at the time of the incident. This is slightly higher than the $5.3 \%$ found in a similar study in ECWA veterinary clinic Bukuru. ${ }^{6}$ It is however worrisome because bites from unvaccinated animals pose a significant risk of rabies infection to the victims. Research has shown that achieving a high vaccine coverage in the canine population will lead to high herd immunity among dogs, ultimately resulting in successful elimination of rabies infection in humans. ${ }^{13}$ Our findings are consistent with what was reported in the Bukuru study and suggest that more needs to be done to achieve this goal.

This study has some limitations. Data on animal bites were only collected from victims who presented to veterinary health facilities and may not be a true representation of bite experiences in the communities. In addition, we could not discuss proportion of bite victims that developed rabies because the records lacked this information.

\section{References}

1. Marine G, Martine H. Humananimal relationships: from daily life to animal-assisted therapies. Annali dell'Istituto Superiore di Sanita. 2011;47(4):397408.

2. Aiyedun JO, Olugasa BO. Identification and analysis of dog use, management practices and implications for rabies control in Ilorin, Nigeria. Sokoto J Vet Sci [Internet]. 2012 [cited 2019 Apr 17];10(2):16. Available from: http://dx.doi.org/10.4314/sokjvs.v $10 \mathrm{i} 2.1$
3. Alabi O, Nguku P, Chukwukere S, Gaddo A, Nsubuga P, Umoh J. Profile of dog bite victims in Jos Plateau State, Nigeria: a review of dog bite records (2006-2008). Pan Afr Med J. 2014;18(Supp 1):1820.

4. NYC Health Department. Report an Animal Bite - DOH [Internet]. 2019 [cited 2019 Apr 18]. Available from: https://www1.nyc.gov/site/doh/hea lth/health-topics/animals-andwildlife-report-animal-bite.page

5. Eke CB, Omotowo IB, Ukoha OM, Ibe BC. Human rabies: Still a neglected preventable disease in Nigeria. Niger J Clin Pract. 2015;18(2):268-272

6. Bata S. I, Dzikwi A. A ADG. Retrospective Study of Dog Bite Cases Reported to ECWA Veterinary Clinic , Bukuru , Plateau State, Nigeria . Sci World J [Internet]. 2011 [cited 2019 Apr 18];6(4):20113. Available from: www.scienceworldjournal.org

7. Esmaeilzadeh F, Rajabi A, Vahedi S, Shamsadiny M, Ghojogh MG, Hatan N. Epidemiology of Animal Bites and Factors Associated With Delays in Initiating Post-exposure Prophylaxis for Rabies Prevention Among Animal Bite Cases : A Population-based Study. J Prev Med Public Heal. 2017;50:2106.

8. National, Population, Commission. Report on the census 2006 final results. Abuja: 2009.

9. Plateau State Government, Plateau State of Nigeria:Nigeria information guide. ( Cited 2015 6thJune).Availablefrom: www.nigeriagalleria.com/Nigeria/ States_Nigeria/Plateau_State.html.

10. Patronek GJ, Slavinski SA. 
Animal bites. Journal of the American Veterinary Medical Association. 2009; 234(3):336345

11. Ghannad MS, Roshanaei G. An epidemiologic study of animal bites in Ilam province Iran. Archives of Iranian medicine, 2012:356-360

12. Sreenivas NS, Sakranaik S,Sobagiah RT, Kumar A. An epidemiology of animalbite cases attending tertiary care centre of BangaloreMedical College and Research Institute, Bengaluru: aretrospective study. Int $\mathbf{J}$ Community Med PublicHealth 2017; 4:2538-42

13. Omoke NI, ChukwuelokaOnyemaechi NO. Incidenceand pattern of dog bite injuries treated in the emergency room of ateaching hospital insouth east Nigeria. Afr J Med Health Sci 2018; 17:35-40.

14. IchhpujaniRL,Mala $\mathrm{C}$, VeenaM,Singh J, Bhardwaj M, Bhattaacharya D et al.

Epidemiology of animal bites and rabies cases in India. A

multicentric study. The journal of communicable diseases. 2008; 40(1):27-36

15. Ngugi NN, Maza AK, Omolo OJ, Obonyo M. Epidemiology and surveillance of human animal-bite injuries and rabies post exposure prophylaxis in selected counties in Kenya, 2011-2016. BMC Public Health. 2018: 18:996.

16. WHO. New Global Framework to Eliminate Rabies [Internet]. 2015[cited 2019 Apr 19]. Available from: https://www.who.int/newsroom/detail/10-12-2015-new-globalframework-t0-eliminate-rabies 